\title{
Removal of Lead from Waste Water using Lantana Camara as Adsorbent
}

\author{
Lavanaya M.B, Boya Nagaraju, Pradeep.M.
}

\begin{abstract}
As we are moving towards the development by urbanization and industrialization on the other hand it is becoming a major environmental impact. Due to the urbanization and industrialization, many processing industries causing major environmental problem, among these problems heavy metal pollution by allowing of industrial waste water into natural water bodies is more dreadful. This is turn increase the heavy metal concentration in natural water bodies resulting in damage to aquatic flora and fauna. The objective of this study is to determine the heavy metal concentration (i.e. Pb) in industrial waste water, in this project waste water from one of the electroplating industries in Bangalore; this study gives knowledge about the percentage removal of lead using lantana camara as an adsorbent. The optimum condition for effective removal of lead is studied by conducting various experiments by varying adsorbent dosage and agitation time and by plotting isotherms, i.e. langmiur isotherms and Freundlich isotherms and pseudo I order and pseudo II order kinematics. This study is carried out using spectrophotometer analysis.

Keywords - adsorbent, adsorbate, adsorbtion, isotherms,
\end{abstract} kinetics, lead, absorbance.

\section{INTRODUCTION}

Environmental heavy metal pollution is mainly of anthropogenic in nature and results from activities such as vehicular emission, industrial activities, fertilizers draining into rivers, sewage and municipal waste etc. Certain plants like lantana camara and commelina benghalensis are good adsorbent in nature after some processing. In this project lantana camara is used as adsorbent for removal of lead, earlier experiments were conducted using lantana camara for removal of other heavy metals such as copper, cadmium, zinc, etc. Lead is of particular interest, because of its toxicity and its widespread presence in environment and it is considered as prior pollutant. Lead may enter water bodies both naturally and can also be induced. Natural source are volcanos, forest fire, weathering of rocks etc., where as it is induced into environment by human activities such as industries, combustion in vehicles, waste management etc. Lead has its adverse effect on both human health and aquatic ecosystem. Lead has adverse behavioral, psychological effect

Revised Manuscript Received on October 30, 2019.

* Correspondence Author

Lavanya. M. B*, Department of Civil Engineering, Sri Venkateshwara College of Engineering, Bangalore, India

Boya Nagaraju, Department of Civil Engineering, Sri Venkateshwara College of Engineering, Bangalore, India

Pradeep. M. Department of Civil Engineering, Sri Venkateshwara College of Engineering, Bangalore, India

(C) The Authors. Published by Blue Eyes Intelligence Engineering and Sciences Publication (BEIESP). This is an open access article under the CC BY-NC-ND license (http://creativecommons.org/licenses/by-nc-nd/4.0/) on humans, where as it leads to bio concentration in skin, bones, kidneys, liver of fishes leading to disturbance in aquatic system. Lead can be removed precipitation, ion exchange, electro-coagulation, cementation, reverse osmosis and adsorption method. In this project adsorption method was selected due to its increased interest and its an alternative for high cost, sensitive conventional technologies. In this project Lantana camara is used as adsorbent due to its property such as hyper accumulation, natural availability and inexpensive. The variations were made in adsorption dosage, agitation time and optimum condition for removal of lead was determined and Freundlich and Langmuir isotherms were drawn along with pseudo I and II order isotherms. This analysis was made using UV spectrophotometer.

\section{MATERIAL AND METHODOLOGY}

\section{A. Material}

Lantana camara (Adsorbent): Lantana camara is a species of flowering plant within the verbena family, plant species accumulates significant amount of the some heavy metals .These plants are hyper accumulative and can be obtained naturally hence it can be effectively used as an in expensive adsorbent for removal of lead from industrial waste water.

\section{B. Equipments}

The equipment's used in this study for different experiment are $\mathrm{pH}$ meter, naphelo turbidity meter, weighing balance, uv spectrophotometer, furnace, hot air oven and water bath.

\section{Methodology}

- Collection of lantana camara sample from agricultural site in Coorg, it is powdered and crushed to smaller size. Particle passing through $0.030 \mathrm{~mm}$ are collected.

- Crushed particle is activated using con Sulphuric acid for better adsorption, heated at $120 \mathrm{oC}$ for 12 hours in furnace then double washed with distilled water and dried in hot air oven for 5 hours at $130 \circ \mathrm{c}$. The dried sample is sieved and particles passing through $.030 \mathrm{~mm}$ and retained over $.015 \mathrm{~mm}$ are collected due to availability of larger surface area.

- Collection of industrial waste water from electroplating industry located in Bangalore.

- Preliminary test on collected sample.

- Modeling analysis of sample by varying adsorbent dosage and agitation time.

- Water sample is tested for percentage removal of lead using spectrophotometer.

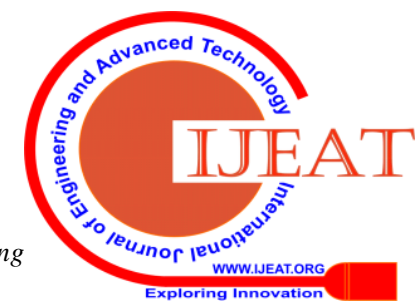


- Test result are tabulated and analyzed using isotherms and kinematics.

\section{TEST RESULT}

\section{A. Preliminary Test Results}

- Preliminary Test Results

- $\mathrm{pH}$ of collected sample from $\mathrm{pH}$ meter was 8.76 and the result from $\mathrm{pH}$ paper was 9 . The $\mathrm{pH}$ value signifies that sample is alkaline in nature.

- Phenol alkalinity of sample was calculated and found out to be $9.5 \mathrm{mg} / \mathrm{lt}$, where as methyl orange alkalinity was found out to be $40.6 \mathrm{mg} / \mathrm{lt}$.

- Available chloride in sample was 18.25 mg/lt.

- Total hardness of industrial waste water was86mg/lt.

- Total solids were measured to be $2600 \mathrm{mg} / \mathrm{lt}$, dissolved solids was found out to be $1066.67 \mathrm{mg} / \mathrm{lt}$, whereas the amount of suspended solids was $1533.33 \mathrm{mg} / \mathrm{lt}$.

- The collected water sample was 17.7NTU turbid.

\section{B. Result of absorbance for various adsorption dosage}

The variation of absorbance with respect to dosage is tabulated in table 1 and graphically represented in figure 1

C. Result of absorbance for varying agitation time

The variation of absorbance with respect to agitation time is tabulated in table 2 and graphically represented in figure 2 .

\section{Langmuir isotherms}

The expression for Langmuir isotherm is given below

$1 / q_{e}=1 /\left(q_{m} K L\right)\left(1 / C_{e}\right)+1 / q_{m}$

Where

$q_{e}=$ amount of solute adsorbed per unit weight of the adsorbent at equilibrium (mg/g)

$q_{m}=$ the maximum adsorption capacity (mg/g)

$C_{e}=$ the equilibrium concentration of the solute in the bulk solution (mg/L)

$K_{L}=$ Langmuir constant.

In terms of a dimensionless equilibrium parameter (RL) the essential characteristics of Langmuir isotherm can be expressed

Where,

$$
R_{L}=1 /\left(1+K_{L} C_{0}\right)
$$

$\mathrm{KL}=$ Langmuir constant,

$\mathrm{C} 0$ = Initial concentration $(\mathrm{mg} / \mathrm{L})$.

The type of the isotherm is indicated from the value of RL.

If $\mathrm{RL}>1$ : Unfavorable: $\mathrm{RL}=1$ : Linear: $\quad 0<\mathrm{RL}<1$ : Favorable: $\quad \mathrm{RL}=0$ : Irreversible.

The data for Langmuir isotherm for various dosage and agitation time and represented in fig 3 and fig 4 respectively

\section{E. Freundlich isotherm}

The expression for Langmuir isotherm is given below

$\log q_{e}=\left(\log \mathrm{K}+1 /(n) \log C_{e}\right)$

where,

$q_{e}=$ amount of solute adsorbed per unit weight of the adsorbent at equilibrium (mg/g)

$C_{e}=$ the equilibrium concentration of the solute in the bulk solution $(\mathrm{mg} / \mathrm{L})$

$\mathrm{KF}$ and $\mathrm{n}=$ Freundlich Isotherm.

Adsorption intensity is measured by the slope $1 / n$ ranging between 0 and 1 .

As the $1 / n$ value gets closer to zero, it becomes more heterogeneous.

A value of $1 / n$ below one indicates unfavorable condition.
$1 / n$ above one is indicative of favorable condition. The data for Freundlich isotherm for various dosage and agitation time represented in fig 4 . And fig 5 respectively.

\section{F. Pseudo I and II order kinematics}

The pseudo I orders and pseudo II order expression are given below and they are represented in fig 6 and fig 7 respectively.

$\left(q \_e-q \_t\right)=\log q \_e-K \_1 / 2.303 \quad t$ pseudo $\mathrm{I}$ order kinematics

$t / q \_t=1 /\left(K \_2 \quad q \_e^{\wedge} 2\right)+1 / q \_e \quad t \quad$ pseudo II order kinematics

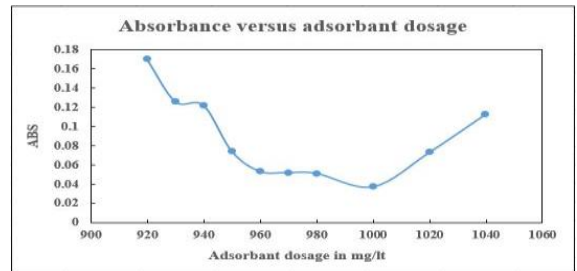

Figure 1 Absorbance variation with dosage

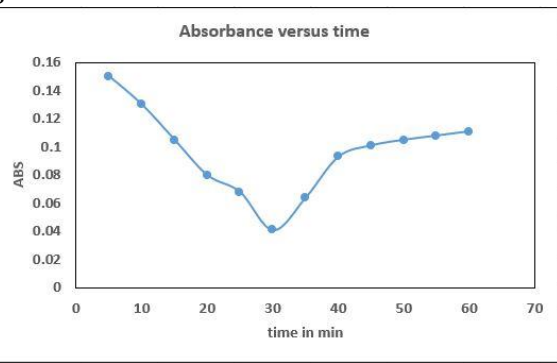

Figure 2 Absorbance variation with time of agitation

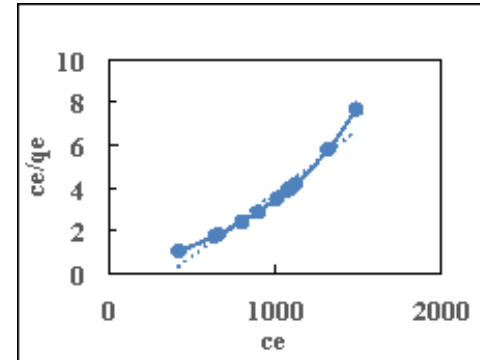

Figure 3 Langmuir isotherm for varying dosage

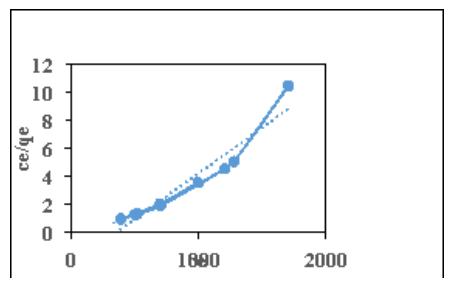

Figure 4 Langmuir isotherm for varying agitation time

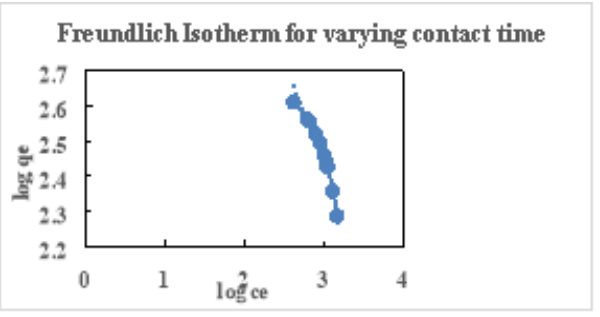

Published By: 


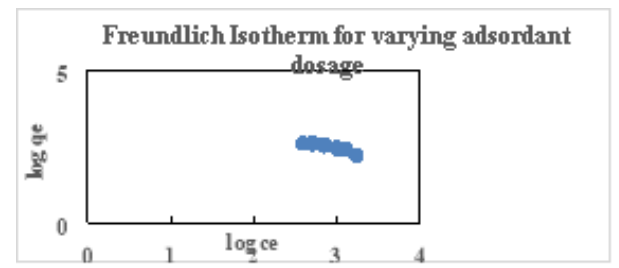

Figure 5 Freundlich Isotherm For Varying Dosage

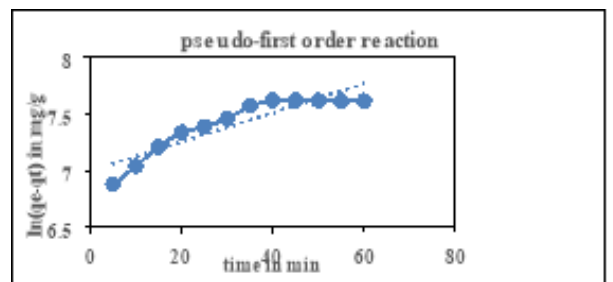

Figure 6 Pseudo first order

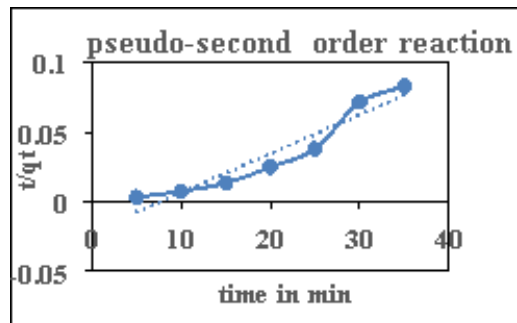

Figure 7 Pseudo second order

\section{CONCLUSION}

\section{Variation of Adsorbant dosage}

Adsorbent dosage takes 920, 930, 940, 950, 960, 970, 980, 1000, 1020 and1040mg/lt.

Optimum dosage obtained: $1000 \mathrm{mg} / \mathrm{lt}$.

Initial concentration of waste water sample $=2460 \mathrm{mg} / \mathrm{lt}$.

After adsorption process by $1000 \mathrm{mg} / \mathrm{lt}$ of adsorbent concentration of the sample $=390 \mathrm{mg} / \mathrm{lt}$.

Percentage removal of lead $=((2460-390) / 2460) * 100$ $=84.15 \%$

\section{Variation of Contact Time}

Time: 5,10,15,20,25,30,35,40,45,50,55 and $60 \mathrm{~min}$.

Optimum: $30 \mathrm{~min}$

Adsorbent dosage: $1000 \mathrm{mg} / \mathrm{lt}$

After adsorption process for $30 \mathrm{~min}$ by $1000 \mathrm{mg} / \mathrm{lt}$ of adsorbent concentration of the sample $=420 \mathrm{mg} / \mathrm{lt}$.

Percentage removal of lead $=((2460-420) / 2460) * 100$ $=82.92 \%$

From the results of batch adsorption kinetic study, shows that pseudo - second order kinetic model provided a good correlation for adsorption of lead from industrial waste water sample. The results of batch adsorption data for Langumir, Freundlich isotherm plots indicated that Langumir adsorption isotherm fitted well for adsorption of lead on Lantana camara sample as an adsorbent.

\section{REFERENCES}

1. Rohan Jeffery Robert, C R Girish,Department of Chemical Engineering Manipal Institute of Technology,Manipal Academy of Higher Education, Manipal, Karnataka ,"The Removal Of Cobalt, Nickel, Cadmium And Lead From Wastewater Using Lantana Camara As Adsorbent", India International Journal of Civil Engineering and Technology (IJCIET),Volume 9, Issue 8, August 2018, http://www.iaeme.com/ijciet/issues.asp

2. Naeema H. Yarkandi, Corresponding author "Removal of lead (II) from waste water by adsorption" Chem. Department- College of Applied
Science, Umm Al-Qura University,Makkah, Saudi Arabia, International Journal of current microbiology and Applied Sciences, ISSN 2319-7706 Volume 3 Number 4 (2014) pp. 207-228, http://www.ijcmas.com

3. A. Dubey, S. Shiwani," Adsorption of lead using a new green material obtained from Portulaca plant”, Int. J. Environ. Sci. Technol. (2012), 22 November 2011

4. Sathya Vani Yadla, V. S. (2006). "Adsorption performance of fly ash for the removal of lead", Delhi

5. Sushil Bachale, Dr. Sarita Sharma, Dr. Ashok Sharma and Dr. Sanjay Verma "Removal of lead (II) from aqueous solution using low cost adsorbent: A review", International Journal of Applied Research, ISSN Print: 2394-7500, ISSN Online: 2394-5869, Impact Factor: 5.2, IJAR 2016; 2(7): 523-527, www.allresearchjournal.com

6. Joshua N. Edokpayi 1, John O. Odiyo 1, Titus A. M. Msagati 2 and Elizabeth O. Popoola 3 "A Novel Approach for the Removal of Lead (II) ion from Wastewater Using Mucilaginous Leaves of Diceriocaryum eriocarpum plant", Open Access Journal,sustainability,ISSN 2071-1050,www.mdpi.com/journal/sustainability,19 October 2015

7. Archana Dixit.S.D,(2005), "Study of adsorption isotherms and thermodynamics for heavy metal removal from aqueous solutions using canna Indica biomass", Dehli

8. Husein:, M. A. (2011). "Removal of strontium from aqueous solutions by adsorption Onto orange peel: isotherms, kinetics, and thermodynamic studies"

9. Mohsen Arbab. S. (2010). "Removal of lead ions from industrial wastewater" Abudhabi.

\section{AUTHORS PROFILE}

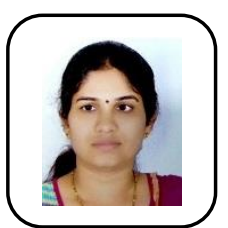

LAVANYA.M.B B.E(Civil Engg), M.E (Environmental Engineering) (PhD) (Environmental Engineering) Assistant Professor, Department of Civil Engineering, Sri Venkateshwara College of Engineering, Bangalore, India Email: lavanaya.chukki@gmail.com.

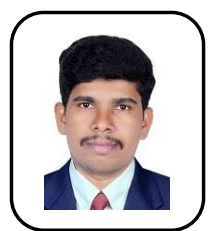

BOYA NAGARAJU, B.E(Civil Engg), M.Tech (Structural Engineering) Assistant Professor, Department of Civil Engineering, Sri Venkateshwara College of Engineering, Bangalore, India, Email:nagarajulook4u@gmail.com

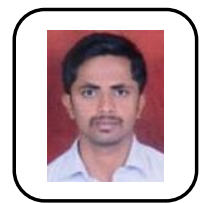

PRADEEP.M. B.E(Civil Engg), M.Tech (Structura Engineering) Assistant Professor, Department of Civil Engineering, Sri Venkateshwara College of Engineering, Bangalore, India, Email:pradeepcivil2012@gmail.com

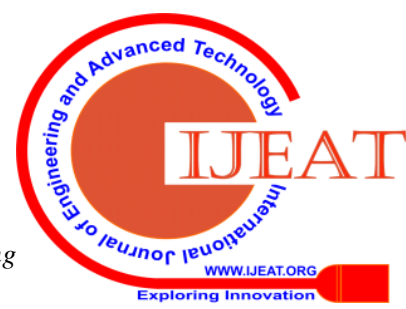

